\title{
Analyzing the gene expression profile of pediatric acute myeloid leukemia with real-time PCR arrays
}

Tao Yan-Fang ${ }^{1}$, Wu Dong ${ }^{1}$, Pang Li', Zhao Wen-Li' ${ }^{1}$, Lu Jun ${ }^{1}$, Wang Na ${ }^{1}$, Wang Jian ${ }^{1}$, Feng Xing ${ }^{1}$, Li Yan-Hong ${ }^{1}$, Ni Jian ${ }^{2}$ and Pan Jian ${ }^{1,2^{*}}$

\begin{abstract}
Background: The Real-time PCR Array System is the ideal tool for analyzing the expression of a focused panel of genes. In this study, we will analyze the gene expression profile of pediatric acute myeloid leukemia with real-time PCR arrays.

Methods: Real-time PCR array was designed and tested firstly. Then gene expression profile of 11 pediatric AML and 10 normal controls was analyzed with real-time PCR arrays. We analyzed the expression data with MEV (Multi Experiment View) cluster software. Datasets representing genes with altered expression profile derived from cluster analyses were imported into the Ingenuity Pathway Analysis Tool.

Results: We designed and tested 88 real-time PCR primer pairs for a quantitative gene expression analysis of key genes involved in pediatric AML. The gene expression profile of pediatric AML is significantly different from normal control; there are 19 genes up-regulated and 25 genes down-regulated in pediatric AML. To investigate possible biological interactions of differently regulated genes, datasets representing genes with altered expression profile were imported into the Ingenuity Pathway Analysis Tool. The results revealed 12 significant networks. Of these networks, Cellular Development, Cellular Growth and Proliferation, Tumor Morphology was the highest rated network with 36 focus molecules and the significance score of 41. The IPA analysis also groups the differentially expressed genes into biological mechanisms that are related to hematological disease, cell death, cell growth and hematological system development. In the top canonical pathways, p53 and Huntington's disease signaling came out to be the top two most significant pathways with a $\mathrm{p}$ value of $1.5 \mathrm{E}-8$ and2.95E-7, respectively.

Conclusions: The present study demonstrates the gene expression profile of pediatric AML is significantly different from normal control; there are 19 genes up-regulated and 25 genes down-regulated in pediatric AML. We found some genes dyes-regulated in pediatric AML for the first time as FASLG, HDAC4, HDAC7 and some HOX family genes. IPA analysis showed the top important pathways for pediatric AML are p53 and Huntington's disease signaling. This work may provide new clues of molecular mechanism in pediatric AML.
\end{abstract}

Keywords: Pediatric, Acute myeloid leukemia, Real-time PCR array

\section{Background}

Pediatric acute myeloid leukemia (AML) comprises up to $20 \%$ of all childhood leukemia. Pediatric AML is a heterogeneous clonal disorder of hematopoietic progenitor cells, which lose the ability to differentiate normally and to respond to normal regulators of proliferation $[1,2]$. Gene microarray technology provides a powerful tool for

\footnotetext{
* Correspondence: panjian2008@163.com

'Department of Hematology and Oncology, Children's Hospital of Soochow University, Suzhou, China

${ }^{2}$ Translational Research Center, Second Hospital, The Second Clinical School, Nanjing Medical University, Nanjing, China
}

characterizing gene expression on a genome scale [3-6]. Both cDNA and oligonucleotide-spotted microarrays have been used to find genes discriminative for the different genetic subgroups of pediatric AML [7]. Most reproducible and extensive results have been obtained using Affymetrix Gene Chips since these microarrays contain multiple perfect matches and mismatch oligonucleotides per gene and have been thoroughly validated. These studies in pediatric AML revealed new insights into the underlying biology of the different leukemic subtypes which

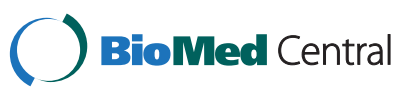

(c) 2012 Yan-Fang et al.; licensee BioMed Central Ltd. This is an Open Access article distributed under the terms of the Creative Commons Attribution License (http://creativecommons.org/licenses/by/2.0), which permits unrestricted use, distribution, and reproduction in any medium, provided the original work is properly cited. 
may point to novel ways to treat these leukemia more specifically [8-10].

While microarray has been widely used in discoverybased medical and basic biological research, its direct application in clinical practice and regulatory decisionmaking has been questioned [11-13]. A few key issues, including the reproducibility, reliability, compatibility and standardization of microarray analysis and results, must be critically addressed before any routine usage of microarrays in clinical laboratory and regulated areas. However, in the absence of a "gold standard" or common reference for gene expression measurements, these evaluations and comparisons have often yield subjective and conflicting conclusions [14-18].

Real-time PCR is widely considered the gold standard for gene expression measurement due to its high assay specificity, high detection sensitivity and wide linear dynamic range. In addition to the TaqMan assay, the $S Y B R^{\circledR}$ Green PCR assay is another commonly used real-time PCR technique which is employed by half of all real-time PCR users. SYBR Green PCR is widely used because of the ease in designing the assays and its relatively low setup and running costs $[19,20]$. One drawback of SYBR Green assays, however, is that the dye is non-specific and can generate false positive signals if non-specific products or primer-dimmers are present in the assay [21]. Those problems can be addressed by carefully designing the primers and validating the PCR products with dissociation curve analysis immediately after PCR.

So the Real-time PCR Array System is the ideal tool for analyzing the expression of a focused panel of genes. The flexibility, simplicity, and convenience of standard SYBR Green PCR detection methodology make the PCR Array System accessible for routine use in any research laboratory [22]. The specificity of the system guarantees the amplification of only one gene-specific product in each reaction meaning that the expression level result confidently reflects only the gene of interest. The present study demonstrates SYBR Green Real-time PCR Arrays to be a quantitative platform with high inter run and inter-laboratory reproducibility. PCR Arrays produce gene profiling differences between the two RNA samples that are highly concordant with those generated by other quantitative gene expression analysis and microarray platforms. PCR Arrays deliver results comparable to those of high-density microarrays. Moreover, it yields results similar to those of TaqMan Gene Expression Assays, a widely accepted method for validating microarray results, and other more complicated and more expensive quantitative methods tested by the TaqMan assay [19].

In this study, we will analyze the dyes-regulation genes and pathways in pediatric AML with this powerful platform, Real-time PCR arrays.

\section{Results and discussion}

\section{Design the Real-time PCR array}

We designed and tested 88 real-time PCR primer pairs for a quantitative gene expression analysis of key genes involved in pediatric AML (Additional file 1). Briefly ,we assayed the expression of 11 genes of $\mathrm{HOX}$ family [HOXA1, HOXA3, HOXA4, HOXA5, HOXA7, HOXA9, HOXB6, HOXB7, HOXB9 and HOXB9], 15 apoptosis related genes [CASP1, CASP4, CASP8, BCL2, BIK, BIRC5, BAX, BCL2L1, S100A8, S100A9, ID1, ID2,ID3, ID4 and TNF], 7 chemokines [CCL5, CCR1, CCR2, CCR4, CCR5 and CXCR4 ], 13 tumor related genes [WT1, BRCA1 ,NF1, RB, APC, TP53BP1, PTEN, TP53 , CDKN1A, CDKN2B, CDKN1C, Jun and CCNB1] and 17 important genes in leukemia[ HMBS, CDH1, STAT4, TIMP1,CD44, CDC42, DDX1, DKK3, HMGB2, STMN1, STMN2, MEIS1, MEIS2, IGFBP3, IL6, LGALS4 and GSK3B]. Each gene was tested the expression analysis and melting curve analysis to make sure the primer is specific for the target gene. The average CV for the CT values generated from assays on the PCR Array is found to be $0.73 \%$ with replicate measurements for CT values below 30 within 0.20 cycle average standard deviation, demonstrating a good inter-run reproducibility.

\section{Expression profile analysis of pediatric AML and normal control samples}

We analyzed gene expression profile of pediatric AML and control samples with our Real-time PCR arrays (Figure 1A). The information of 10 normal control and 11 pediatric AML samples are listed in Table 1. After we get the original data, we analyzed the expression data with MEV (Multi Experiment View) cluster software. The gene expression profile of pediatric AML is significantly different from normal control, set of genes can be successfully clustered (Figure 1B). The results showed compared with normal control, there are 19 genes upregulated and 25 genes down-regulated in pediatric AML (Table 2 and 3). The detailed expression of each up-regulated gene in pediatric AML was presented in Figure 2 and the expression of down-regulated genes was presented in Figure 3. Some of the dyes-regulated genes are consistent with other's report, such as BIRC5, WT1, BCL2, S100A8 and CDKN2B. Oto et al. showed high expression of survivin in AML and survivn is a bad prognostic indicator in cases with acute leukemia especially in AML [23]. Barragan et al. showed that the Wilms' tumor (WT1) gene is over expressed in patients with most forms of acute leukemia. WT1 expression was significantly higher in AML patients than in normal controls ( $p=0.0001$ ) [24]. Twenty-five patients with ALL and 65 patients with AML, both recently diagnosed, were included into a study. A high frequency of BCL2 mRNA over expression and a relatively low frequency of 

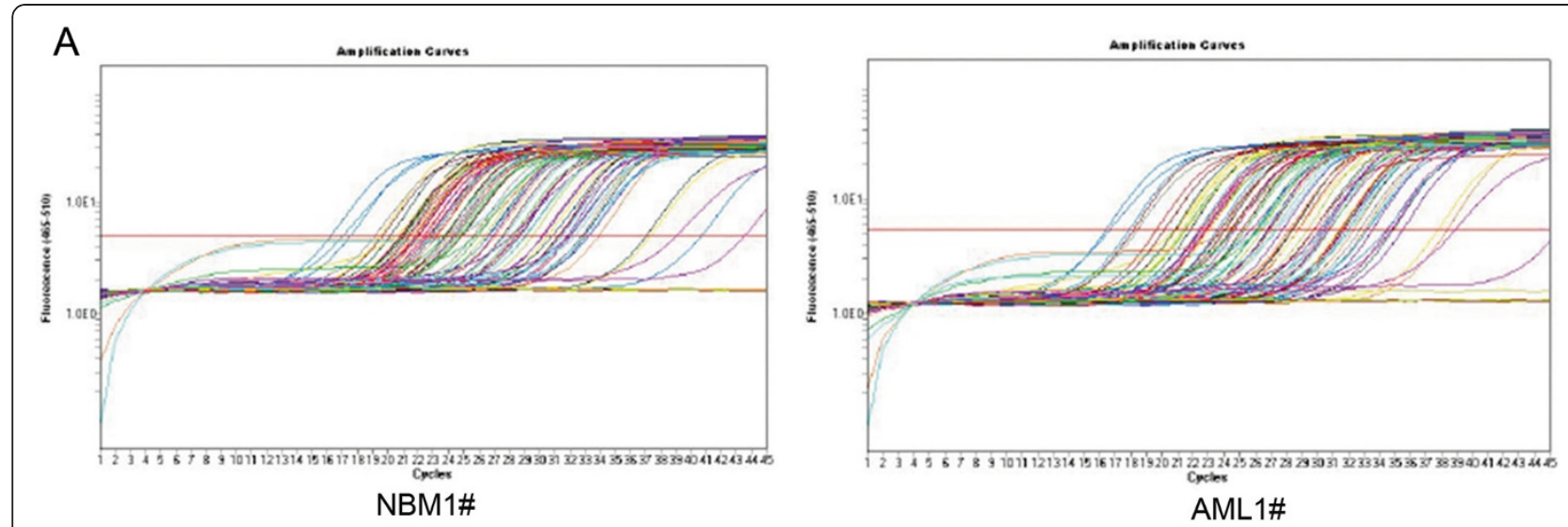

B

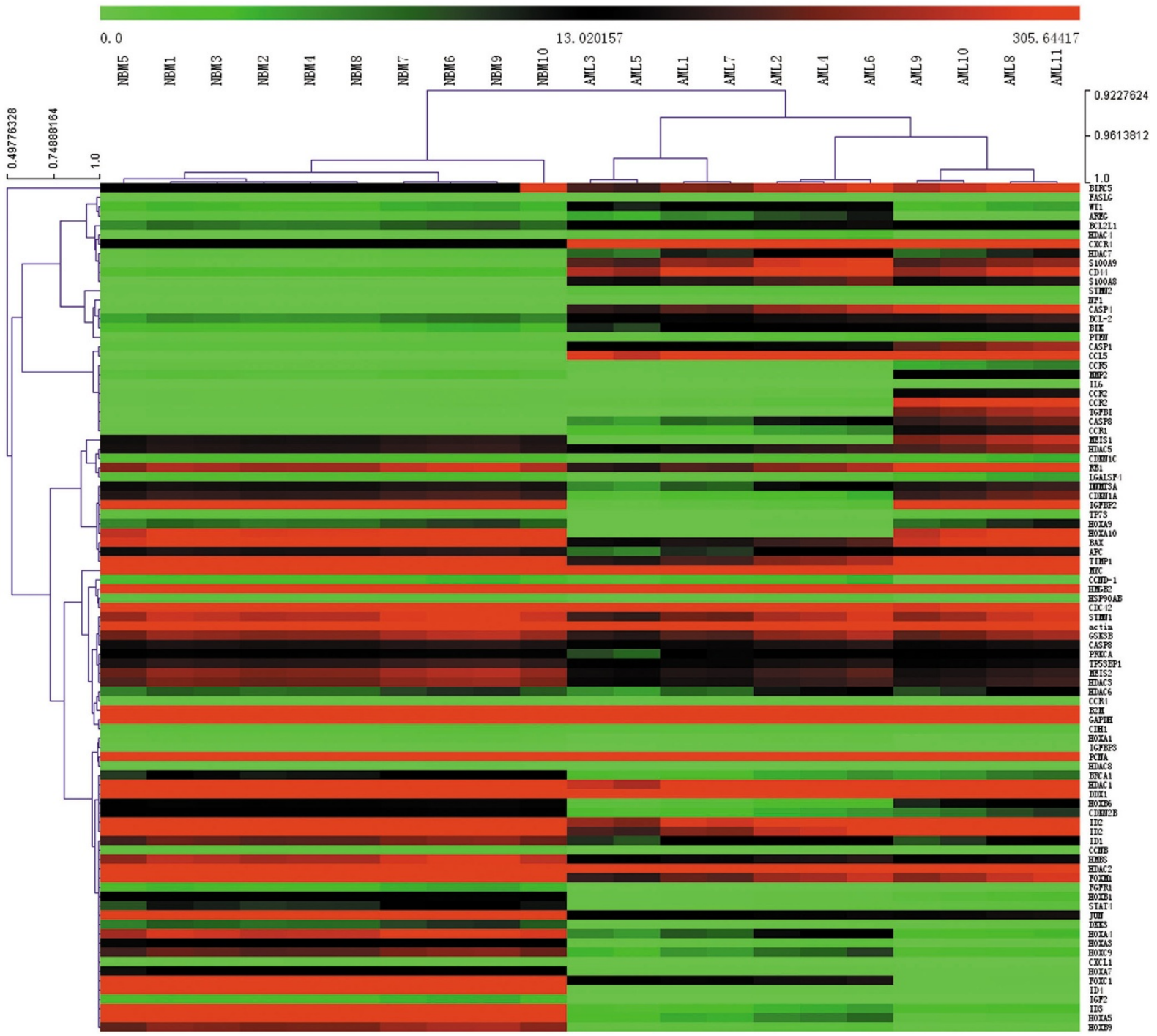

Figure 1 Expression profile analysis of pediatric AML and normal control samples. (A) Amplification data of Real-time PCR arrays in the NBM and pediatric AML. (B) Cluster analysis the data from Real-time PCR arrays. 
Table 1 Pediatric acute myeloid leukemia patients' clinical feature

\begin{tabular}{|c|c|c|c|c|c|c|c|c|c|}
\hline & Age & Sex & $\mathrm{Hb}$ & WBC & $\mathrm{RBC}$ & PLt & Diagnosis & Chromosome & Fusion gene \\
\hline 1 & 7 & M & 80 & 455.8 & 2. 88 & 15 & AML- M1 & $46, X Y$ & HOX11 \\
\hline 2 & 4 & $\mathrm{~F}$ & 83 & 136. 1 & 3. 09 & 11 & AML- M1 & $46, X Y$ & ns \\
\hline 3 & 5 & $\mathrm{~F}$ & 73 & 38.83 & 2. 25 & 14 & AML- M5b & $46, X Y, t(1,11)(q 21 ; q 23)$ & ns \\
\hline 4 & 9 & M & 45 & 2. 47 & 1. 49 & 10 & AML- M3 & $46, X Y, t(11 ; 21), t(15 ; 17)[12] / 46, X Y,[3]$ & PML/ RARA \\
\hline 5 & 0.9 & $\mathrm{~F}$ & 76 & 56.95 & 3. 52 & 155 & AML- M4b & ns & MLL/ AF19 \\
\hline 6 & 3 & M & 82 & 19. 58 & 2. 68 & 11 & AML- M7 & $46, X Y, t(2 ; 16)(q 37 ; q 12), t(12,20)(p 13, q 11)$ & ns \\
\hline 7 & 0.9 & $\mathrm{~F}$ & 73 & 323.54 & 2. 74 & 33 & $A M L-M 4 b$ & ns & ns \\
\hline 8 & 4 & M & 80 & 7. 97 & 2. 3 & 91 & AML- M5 & ns & $\mathrm{AML} / \mathrm{ETO}$ \\
\hline 9 & 11 & M & 80 & 35.3 & 2. 45 & 75 & AML- M3a & $46, X Y$ & PML/ RAR1 \\
\hline 10 & 6 & M & 68 & 39.4 & 2. 39 & 18 & AML- M3 & $46, X Y$ & PML/ RARA \\
\hline 11 & 7 & $\mathrm{~F}$ & 54 & 4. 56 & 1. 75 & 17 & AML- M3 & $46, X X, t(15 ; 17)$ ( q22; q21) [ 3] / 46,XX[ 12] & PML/ RARA \\
\hline
\end{tabular}

$H b$ : Hemoglobin WBC: White blood cells RBC: Red blood cells PLt: Platelet.

BAX mRNA over expression detected in both analyzed leukemia in this study, indicate that altered transcription of these genes may be involved in leukemogenesis [25]. Nicolas et al. used mass spectrometry (MS)-based proteomic approaches to characterize that S100A8 is upregulated in leukemia cells and the expression of S100A8 in leukemic cells is a predictor of low survival [26]. CDKN2B appears to be frequently deleted and methylated in AML [27-30].

This work also indicates some genes dyes-regulated in pediatric AML for the first time. FASLG, the protein encoded by this gene is the ligand for FAS. Interaction of FAS with this ligand is critical in triggering apoptosis of some types of cells such as lymphocytes. The Fas/FasL system as an important pathway inducing cell apoptosis participates in occurrence and development of leukemia. Leukemia cells generally are not sensitive or are resistant to Fas/FasL-mediated apoptosis, while it is one of important reasons resulting in immunoescape and unsensitivity of leukemia cells to chemotherapy. In recent years studies related to mechanisms of leukemia cell resistance to Fas/FasL-mediated apoptosis such as Fas and FasL mutation and expression abnormality, Fas signaling transduction pathway abnormality, and regulatory affect

Table 2 Genes up regulated in the pediatric acute myeloid leukemia compared with normal control

\begin{tabular}{|c|c|c|c|c|c|c|}
\hline & Gene & Description & NBM & AML & Fold change & $\mathbf{P}$ \\
\hline 1 & BI RC5 & Baculoviral IAP repeat containing 5,survivin & 34. 0496 & 221.4575 & 6.504 & $<0.000$ \\
\hline 2 & FASLG & Fas ligand (TNF superfamily, member 6) & 0.0005 & 0.0308 & 57. 068 & $<0.000$ \\
\hline 3 & WT1 & Wilms tumor 1 & 3. 7431 & 14. 5000 & 3. 874 & $<0.000$ \\
\hline 4 & AREG & Amphiregulin & 0.9960 & 4. 6307 & 4. 649 & $<0.000$ \\
\hline 5 & BCL2L1 & BCL2-like 1 & 7. 6435 & 27. 1093 & 3. 547 & 0.0002 \\
\hline 6 & HDAC4 & Histone deacetylase 4 & 0. 0924 & 1. 0273 & 11. 117 & 0.0002 \\
\hline 7 & CXCR4 & Chemokine (C-X-C motif) receptor 4 & 24. 1547 & 1029. 2052 & 42. 609 & 0.0004 \\
\hline 8 & HDAC7 & Histone deacetylase 7 & 0.7191 & 11.6169 & 16. 155 & 0.0006 \\
\hline 9 & S100A9 & S100 calcium binding protein A9 & 0.4583 & 185. 0090 & 403. 722 & 0.0007 \\
\hline 10 & CD44 & CD44 molecule (Indian blood group) & 2. 1648 & 312. 4866 & 144. 349 & 0.0007 \\
\hline 11 & S100A8 & S100 calcium binding protein A8 & 0.0027 & 79. 0206 & 29736.015 & 0.0007 \\
\hline 12 & STMN2 & Stathmin-like 2 & 0.1887 & 1. 2260 & 6.497 & 0.0007 \\
\hline 13 & NF1 & Neurofibromin 1 & 0.0553 & 0.3749 & 6.775 & 0.0009 \\
\hline 14 & CASP4 & Caspase 4 & 0.1491 & 218. 1356 & 1463. 137 & 0.0009 \\
\hline 15 & $\mathrm{BCL}-2$ & B-cell CLL/lymphoma 2 & 6. 1230 & 60.3025 & 9. 849 & 0.0009 \\
\hline 16 & $\mathrm{BI} \mathrm{K}$ & BCL2-interacting killer (apoptosis-inducing) & 3. 3040 & 26. 2063 & 7. 932 & 0.001 \\
\hline 17 & PTEN & Phosphatase and tensin homolog & 0.5800 & 1.4595 & 2. 516 & 0.001 \\
\hline 18 & CASP1 & Caspase 1 & 0.3028 & 79.9140 & 263. 884 & 0.004 \\
\hline 19 & CCL 5 & Chemokine (C- $\mathrm{C}$ motif) ligand 5 & 0.0288 & 872. 0606 & 30237.515 & 0.004 \\
\hline
\end{tabular}

NBM: Mean value of the gene expression in NBM group AML: Mean value of the gene expression in pediatric AML group. 
Table 3 Genes down regulated in the pediatric AML compared with normal control

\begin{tabular}{|c|c|c|c|c|c|c|}
\hline & Gene & Description & NBM & AML & Fold Change & $\mathbf{P}$ \\
\hline 1 & HOXB9 & Homeobox B9 & 172. 9526 & 0.6802 & 0.004 & $<0.0001$ \\
\hline 2 & HOXA5 & Homeobox A5 & 925.5920 & 3. 4967 & 0.004 & $<0.0001$ \\
\hline 3 & I D3 & I nhi bi t or of DNA bi ndi ng 3 & 531.6130 & 3. 0212 & 0.006 & $<0.0001$ \\
\hline 4 & I GF2 & Insulin-like growth factor 2 & 3. 4683 & 0.0056 & 0.002 & $<0.0001$ \\
\hline 5 & I D4 & I nhi bi t or of DNA bi ndi ng 4 & 1422. 5193 & 0.1906 & 0.000 & $<0.0001$ \\
\hline 6 & FOXC1 & Forkhead box C1 & 3676.7938 & 26.5854 & 0.007 & $<0.0001$ \\
\hline 7 & HOXA7 & Homeobox A7 & 15.3933 & 0.2396 & 0.016 & $<0.0001$ \\
\hline 8 & CXCL1 & Chemokine (C-X-C motif) ligand 1 & 0.1130 & 0.0022 & 0.020 & $<0.0001$ \\
\hline 9 & HOXC9 & Homeobox C9 & 138. 5471 & 4. 6762 & 0.034 & $<0.0001$ \\
\hline 10 & HOXA3 & Homeobox A3 & 16. 0470 & 0.5843 & 0.036 & $<0.0001$ \\
\hline 11 & HOXA4 & Homeobox A4 & 263.9704 & 7. 3403 & 0.028 & $<0.0001$ \\
\hline 12 & DKK3 & Dickkopf 3 homolog & 8. 4810 & 0.3344 & 0.039 & $<0.0001$ \\
\hline 13 & JUN & Jun pr ot o- oncogene & 1005. 8731 & 35. 1804 & 0.035 & $<0.0001$ \\
\hline 14 & STAT4 & Signal transducer and activator of transcription 4 & 11.5854 & 0.5332 & 0.046 & $<0.0001$ \\
\hline 15 & HOXB1 & Homeobox B1 & 23. 4942 & 0.8037 & 0.034 & $<0.0001$ \\
\hline 16 & FGFR1 & Fibroblast growth factor receptor 1 & 3. 7172 & 0.2184 & 0.059 & $<0.0001$ \\
\hline 17 & FOXM1 & For khead box M1 & 789. 1920 & 177. 9791 & 0.226 & 0.0008 \\
\hline 18 & HDAC2 & Histone deacetylase 2 & 2925.0236 & 618.9588 & 0.212 & 0.0008 \\
\hline 19 & HMBS & Hydr oxymet hyl bi I ane synt hase & 233. 0075 & 46. 3417 & 0.199 & 0.0008 \\
\hline 20 & I D1 & I nhi bi t or of DNA bi ndi ng 1 & 140. 4811 & 14. 8120 & 0.105 & 0.0008 \\
\hline 21 & I D2 & I nhi bi t or of DNA bi ndi ng 2 & 1221.3259 & 360.7765 & 0.295 & 0.001 \\
\hline 22 & CDKN2B & Cyclin-dependent kinase inhibitor $2 \mathrm{~B}$ & 23. 9879 & 5. 1419 & 0.214 & 0.001 \\
\hline 23 & DDX1 & DEAD ( Asp- Gl u- Al a- Asp) box hel i case 1 & 2039.8291 & 681.2089 & 0.334 & 0.001 \\
\hline 24 & $\mathrm{HDAC1}$ & Histone deacetylase 1 & 1196. 1914 & 449. 9266 & 0.376 & 0.002 \\
\hline 25 & BRCA1 & $\mathrm{Br}$ east cancer 1 , ear I y onset & 12. 8548 & 4. 4127 & 0.343 & 0.004 \\
\hline
\end{tabular}

NBM: Mean value of the gene expression in NBM group AML: Mean value of the gene expression in pediatric AML group.

of apoptotic regulatory genes on Fas/FasL system, as well as strategies replying to antiapoptosis of leukemia cells including NF-kappa B, XIAP, membrane receptor CD28 and matrix metalloproteinase 7 obtained some progresses [31]. HDACs, this work showed HDAC4 and HDAC7 up-regulated, HDAC1 and HDAC2 downregulated in pediatric AML. Recruitment of HDAC4 is necessary for PLZF-mediated repression in both normal and leukaemic cells [32]. Ectopic expression of PML recruits HDAC7 to PML NBs and leads to activation of MEF2 reporter activity [33]. HDACs 1 is critical in enhancing cytarabine-induced apoptosis in pediatric AML, at least partly mediated by Bim [34]. Evaluated the mRNA gene expression profile of 12 HDAC genes by quantitative real-time polymerase chain reaction in 94 consecutive childhood acute lymphoblastic leukaemia (ALL) samples and its association with clinical/biological features and survival. ALL samples showed higher expression levels of HDAC2, HDAC3, HDAC8, HDAC6 and HDAC7 when compared to normal bone marrow samples. HDAC1 and HDAC4 showed high expression in T-ALL and HDAC5 was highly expressed in B-lineage
ALL [35]. And these results may indicate a different expression profile of histone deacetylases (HDACs) between pediatric ALL and AML. Histones play a critical role in transcriptional regulation, cell cycle progression, and developmental events. HDACs is common feature in several human malignancies and may represent an interesting target for cancer treatment, including hematological malignancies. This work also found 7 HOX genes down-regulated in pediatric AML. HOX gene transcription during definitive hematopoiesis is tightly regulated, but in a temporal manner [36]. In AML, increased expression of HoxB3, B4, A7-11 is found in the most primitive progenitors with expression of A7-11 aberrantly sustained in differentiating progenitors $[37,38]$. This study indicate an novel profile of HOX genes down-regulated in pediatric AML and these observations suggest that analyzing the expression profile of HOX genes would provide useful insights into pediatric myeloid leukemogenesis. Expression of HOX B6 and HOX B9 in NB4 and HL-60cells increase at a mid stage of myeloid differentiation by ATRA induction and then decrease during a late stage [39]. The phenotypic survey 


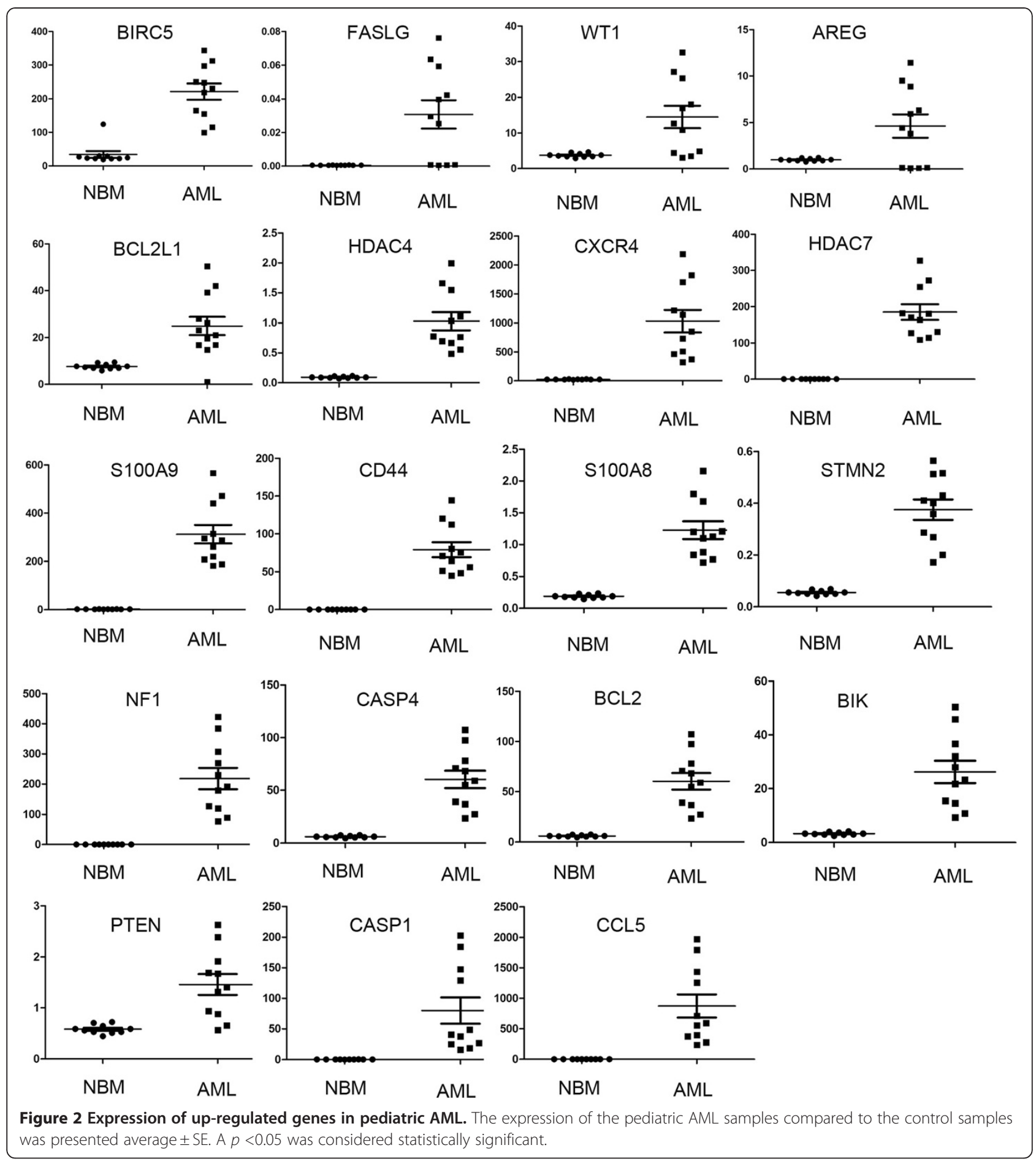

of Hoxa5 mutant mice has unveiled the crucial role of this gene in regulating morphogenesis and specifying regional identity along the embryo. A majority of Hoxa5 mutant pups die at birth from defective respiratory tract. Surviving mutants present deficient alveolar septation revealing the importance of Hoxa5 during formation and maturation of the lung. The implication of Hoxa5 in tumorigenesis has also been documented, the loss of Hoxa5 function limits leukaemia associated with specific chromosomal translocations. Thus, inappropriate Hoxa5 gene expression may disrupt normal growth and differentiation programs causing neoplasia [40]. Hypermethylation of HOXA5 is a good prognostic factor of AML patients. The patients of the AML group who had high 

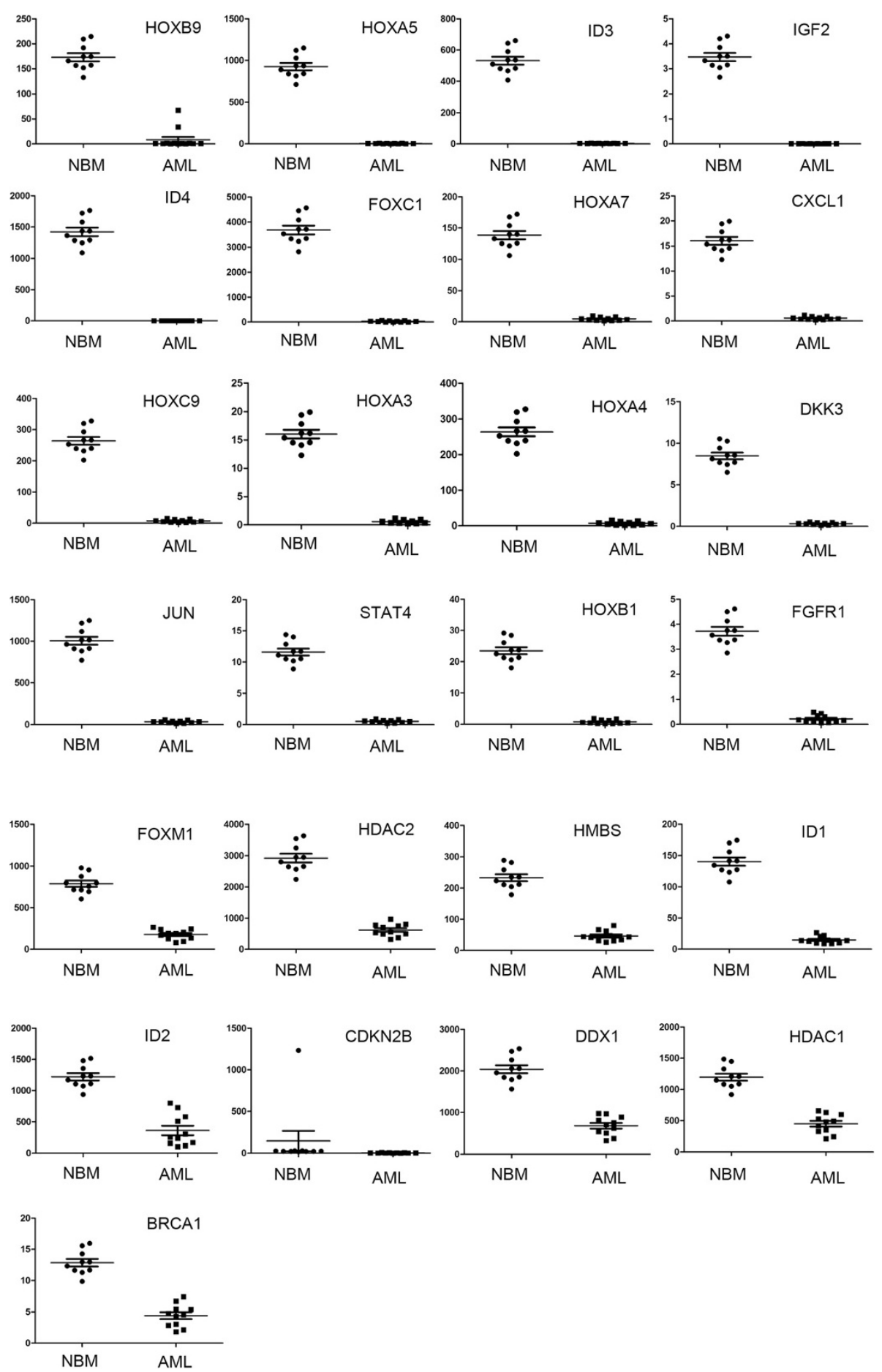

Figure 3 Expression of down-regulated genes in pediatric AML. The expression of the pediatric AML samples compared to the control samples was presented average \pm SE. A $p<0.05$ was considered statistically significant.

methylation percentage had a good prognosis with a 3-yr overall survival. Cox proportional hazards regression showed that the methylation percentages of HOXA5 were independently associated with the 3-year overall survival of AML patients [36]. HOXA4 gene expression is a predictor for outcome in normal karyotypic AML patients. 
77\% AML patients with HOXA4 hypermethylated and the low HOXA4 expression is a favourable predictor for outcome in AML patients [41].

\section{Ingenuity pathway analysis the dyes-regulated genes in pediatric AML}

To investigate possible biological interactions of differently regulated genes, datasets representing genes with altered expression profile derived from real-time PCR array analyses were imported into the Ingenuity Pathway Analysis Tool. The list of differentially expressed genes analyzed by IPA revealed 12 significant networks. Figure 4A represents the list of top 4 networks identified by IPA. Of these networks, Cellular Development, Cellular Growth and Proliferation, Tumor Morphology was the highest rated network with 36 focus molecules and the significance score of 41 (Figure 4D). The score is the probability that a collection of genes equal to or greater than the number in a network could be achieved by chance alone. A score of 3 indicates a 1/1000 chance that the focus genes are in a network not due to random chance.

The IPA analysis also groups the differentially expressed genes into biological mechanisms that are related to cancer groups, hematological disease, cell death, cell growth and proliferation, cardiovascular system development and function, tumor morphology and hematological system development and function (Figure 4B). In the toxicology list, p53 and Huntington's disease signaling came out to be the top two most significant pathways with a $\mathrm{p}$ value of $1.5 \mathrm{E}-8$ and2.95E-7, respectively (Figure $4 \mathrm{C}$ ). The genes associated with the top toxicology list are also given in the Additional file 2.

This IPA analysis showed in pediatric AML the top important pathways are p53 and Huntington's disease signaling. P53 protein expression has been widely investigated in leukemia and there are hundreds of papers about the important roles of p53 in the pediatric leukemia [42-50]. But there is still no report about the relationship between Huntington's disease signaling and AML. This work may provide new clues of molecular mechanism in pediatric AML.

\section{Conclusions}

The present study demonstrates the gene expression profile of pediatric AML is significantly different from normal control; there are 19 genes up-regulated and 25 genes down-regulated in pediatric AML. We found some genes dyes-regulated in pediatric AML for the first time as FASLG, HDAC4, HDAC7 and some HOX family gene. IPA analysis showed the top important pathways for pediatric AML are p53 and Huntington's disease signaling. This work may provide new clues of molecular mechanism in pediatric AML.

\section{Methods}

\section{Patients and samples}

Bone marrow specimens were obtained at the time of diagnosis during routine clinical assessment of 11 patients with AML, who presented at the Department of Hematology and Oncology, Children's Hospital of Soochow University between 2011 and 2012. Ethical approval was provided by the Children's Hospital of Soochow University Ethics Committee (No. SUEC2010-011), and informed consent was obtained from the parents or guardians. AML diagnosis was made in accordance with the revised French-American-British (FAB) classification. The main clinical and laboratory features of the patients cohort are summarized in Table 1. Additionally, bone marrow samples from 10 healthy donors were analyzed as controls. Bone marrow mononuclear cells (BMNCs) were isolated using Ficoll solution within $2 \mathrm{~h}$ after bone marrow samples harvested and immediately subjected for the extraction of total RNA.

\section{RNA extraction}

For RNA extraction, bone marrow samples were immediately submerged in $2 \mathrm{ml}$ Trizol (Invitrogen), stored at $-80^{\circ} \mathrm{C}$ until further processed. A volume of $1 \mathrm{ml}$ of each sample was spun at $4^{\circ} \mathrm{C}$ for $15 \mathrm{~min}$ at $12,000 \mathrm{~g}$ to remove debris and DNA, $1 \mathrm{ml}$ of supernatant was mixed with 200 ul chloroform, shaken for 15 seconds, incubated at RT for 2-3 minutes and spun for $10 \mathrm{~min}$ at $12,000 \mathrm{~g}$ at $4^{\circ} \mathrm{C}$. RNA was precipitated by adding $500 \mathrm{ul}$ of the aqueous phase to an equal volume of isopropanol and spun at $14,000 \mathrm{~g}$ at $4^{\circ} \mathrm{C}$ for $10 \mathrm{~min}$. RNA was washed with $75 \%$ ethanol, spun at $14,000 \mathrm{~g}$ at $4^{\circ} \mathrm{C}$ for $10 \mathrm{~min}$, dried and resuspended in $40 \mathrm{ul}$ DEPC-treated $\mathrm{H} 2{ }_{\mathrm{O}}$. The final RNA concentration was determined using a spectrophotometer (Nanodrop 2000) and the purity was assessed by agarose gel electrophoresis.

\section{CDNA synthesis}

CDNA synthesis was performed on 4 ug of RNA in a 10 ul sample volume using SuperScript II reverse transcriptase (Invitrogen) as recommended by the manufacturer. The RNA was incubated with 0.5 ug of oligo (dT) 1218 mers primers (Invitrogen) for $7 \mathrm{~min}$ at $70^{\circ} \mathrm{C}$ and then transferred onto ice. Then, $9 \mathrm{ul}$ of a master mix containing $4 \mathrm{ul}$ of SuperScript II buffer, 2 ul of 0.1 M DTT (Invitrogen), and 1 ul each of dNTPs stock (10 mM) (Invitrogen), Rnasin (40 UI) (Promega) and SuperScript II (Invitrogen) were added to the RNA sample, spun and incubated at $42^{\circ} \mathrm{C}$ for $60 \mathrm{~min}$ followed by $5 \mathrm{~min}$ at $70^{\circ} \mathrm{C}$ to inactivate the enzyme. CDNA was stored at $-20^{\circ} \mathrm{C}$.

\section{Real-time PCR array design and test}

Most of the primers were from a database of Real-time primers, Center for Medical Genetics (http://medgen. 


\section{A Top Networks}

\begin{tabular}{llc} 
ID & Associated Network Functions & Score \\
\hline 1 & Cellular Development, Cellular Growth and Proliferation, Tumor Morphology & 41 \\
2 & Cell Death, Embryonic Development, Tumor Morphology & 16 \\
3 & Cancer, Hematological Disease, Cell Cycle & 14 \\
4 & Connective Tissue Development and Function, Embryonic Development, Organ Development & 12
\end{tabular}

\section{B Top Bio Functions}

\begin{tabular}{|c|c|c|}
\hline Name & $\mathrm{p}$-value & \# Molecules \\
\hline Cancer & $1.38 \mathrm{E}-12-9.49 \mathrm{E}-03$ & 36 \\
\hline Gastrointestinal Disease & 4.33E-11-9.49E-03 & 27 \\
\hline Hematological Disease & $8.05 \mathrm{E}-11-7.94 \mathrm{E}-03$ & 18 \\
\hline Reproductive System Disease & $2.13 \mathrm{E}-10-9.49 \mathrm{E}-03$ & 26 \\
\hline Respiratory Disease & $1.72 \mathrm{E}-09-3.17 \mathrm{E}-03$ & 15 \\
\hline
\end{tabular}

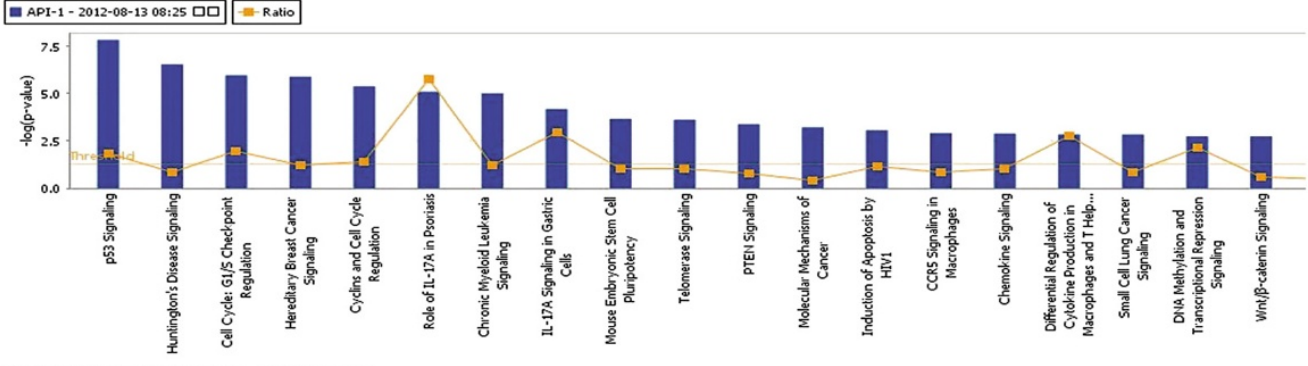

๑2000-2012 Ingenuity Systems, Inc. All rights reserve

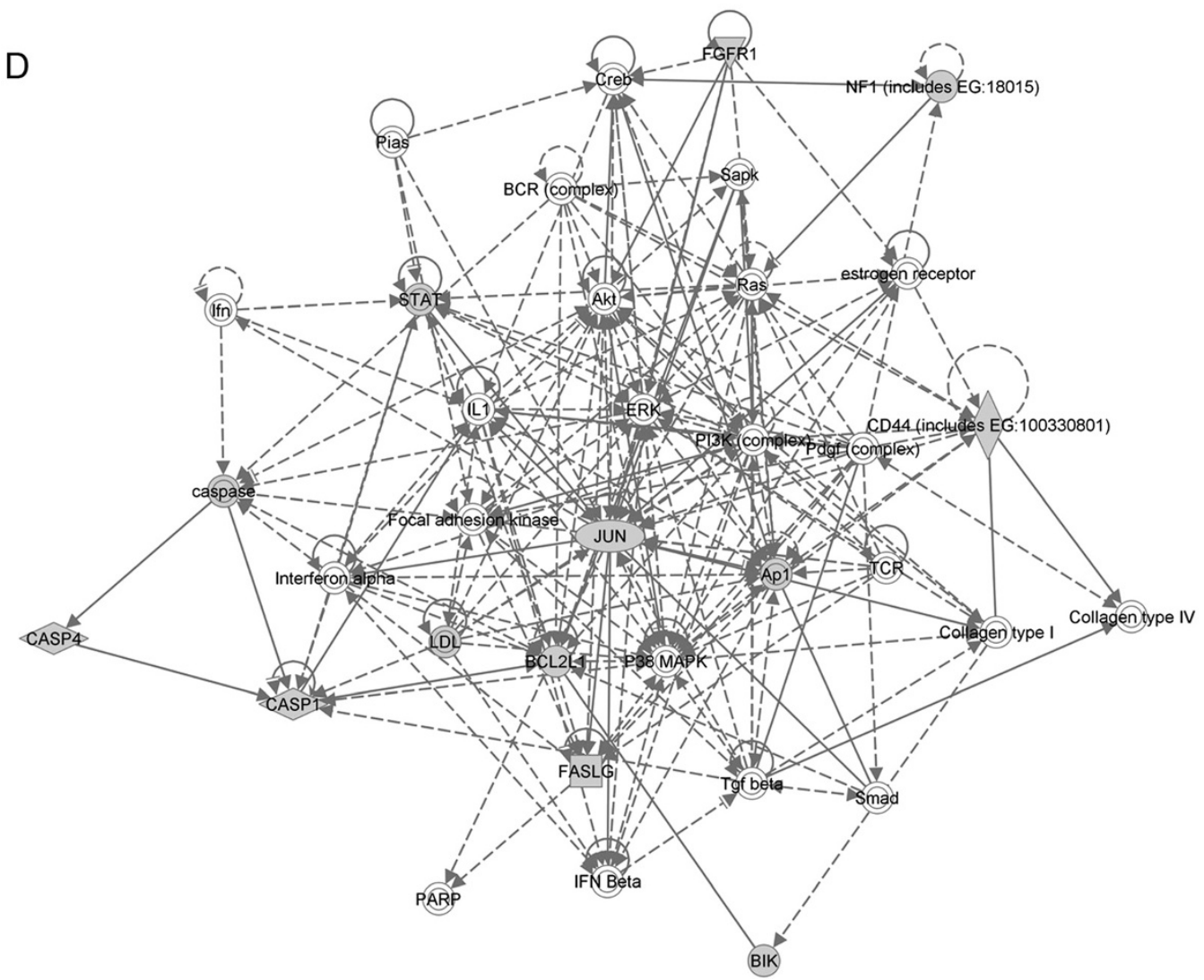

Figure 4 (See legend on next page.) 
(See figure on previous page.)

Figure 4 Ingenuity Pathways Analysis (IPA) summary. (A) The list of top four networks with their respective scores obtained from IPA. (B) The list of top five bio functions with their respective scores obtained from IPA. (C) Toxicology pathway list in IPA analysis. The $x$-axis represents the top toxicology functions as calculated by IPA based on differentially expressed genes are highlighted and the $y$-axis represents the ratio of number of genes from the dataset that map to the pathway and the number of all known genes ascribed to the pathway. The yellow line represents the threshold of $\mathrm{p}$ value, 0.05 as calculated by Fischer's test. (D) Most highly rated network in IPA analysis. The network representation of the most highly rated network. The genes that are shaded were determined to be significant from the statistical analysis. A solid line represents a direct interaction between the two gene products and a dotted line means there is an indirect interaction.

ugent.be/CMGG/). The rest of primers were designed using the online program Primer 3 (www.fokker.wi.mit. edu/primer3/input.htm). Primer selection parameters were set to primer size: 20-26 nts; primer melting temperature: 60 to $64^{\circ} \mathrm{C}$; GC clamp: 1 ; and product size range: generally $120-240 \mathrm{bp}$ but down to $100 \mathrm{bp}$ if no appropriate primers could be identified. Primers were ordered from Invitrogen. (Genes and sequence of the primers was presented in Additional file 1).

\section{Real-time PCR array analysis}

Real-time PCR array analysis was performed in a total volume of $20 \mathrm{ul}$ including $2 \mathrm{ul}$ of cDNA, primers (0.2 mM each) and $10 \mathrm{ul}$ of SYBR Green mix (Roche). Reactions were run on an Light cycler 480 (Roche) using the universal thermal cycling parameters $\left(95^{\circ} \mathrm{C} 5 \mathrm{~min}\right.$, 45 cycles of $10 \mathrm{sec}$ at $95^{\circ} \mathrm{C}, 20 \mathrm{sec}$ at $60^{\circ} \mathrm{C}$ and $15 \mathrm{sec}$ at $72^{\circ} \mathrm{C}$; melting curve: $10 \mathrm{sec}$ at $95^{\circ} \mathrm{C}, 60 \mathrm{sec}$ at $60^{\circ} \mathrm{C}$ and continues melting). Results were obtained using the sequence detection software Light cycler 480 and analyzed using Microsoft Excel. For all samples melting curves were acquired for quality control purposes. For gene expression quantification, we used the comparative $\mathrm{Ct}$ method. First, gene expression levels for each sample were normalized to the expression level of the housekeeping gene encoding Glyceraldehydes 3-phosphate dehydrogenase $(\mathrm{GAPDH})$ within a given sample $(-\Delta \mathrm{Ct})$; the relative expression of each gene was calculated with $10^{6} * \log _{2}(-\Delta \mathrm{Ct})$. The difference between the pediatric AML samples compared to the control samples was used to determine the $10^{6} * \log _{2}(-\Delta \mathrm{Ct})$. Statistical significance of the gene expression difference between the AML and the control samples was calculated with the T-test using SPSS 11.5 software.

\section{Ingenuity pathway analysis (IPA)}

Datasets representing genes with altered expression profile derived from Real-time PCR array analyses were imported into the Ingenuity Pathway Analysis Tool (IPA Tool; Ingenuity $\mathrm{H}$ Systems, Redwood City, CA, USA; http://www.ingenuity.com). In IPA, differentially expressed genes are mapped to genetic networks available in the Ingenuity database and then ranked by score. The basis of the IPA program consists of the Ingenuity Pathway Knowledge Base (IPKB) which is derived from known functions and interactions of genes published in the literature. Thus, the IPA Tool allows the identification of biological networks, global functions and functional pathways of a particular dataset. The program also gives the significance value of the genes, the other genes with which it interacts, and how the products of the genes directly or indirectly act on each other, including those not involved in the microarray analysis. The networks created are ranked depending on the number of significantly expressed genes they contain and also list diseases that were most significant. A network is a graphical representation of the molecular relationships between molecules. Molecules are represented as nodes, and the biological relationship between two nodes is represented as an edge (line). All edges are supported by at least 1 reference from the literature, from a textbook, or from canonical information stored in the Ingenuity Pathways Knowledge Base.

\section{Statistical analysis}

SPSS v11.5 (SPSS Inc., Chicago, IL) was used for statistical analysis. For gene expression quantification, we used the comparative $\mathrm{Ct}$ method. First, gene expression levels for each sample were normalized to the expression level of the housekeeping gene encoding Glyceraldehydes 3-phosphate dehydrogenase (GAPDH) within a given sample $(-\Delta \mathrm{Ct})$; the relative expression of each gene was calculated with $10^{6} * \log _{2}(-\Delta \mathrm{Ct})$. The expression of the pediatric AML samples compared to the control samples was presented average \pm SE. A $p<0.05$ was considered statistically significant.

\section{Additional files}

Additional file 1: Genes and PCR primers of Real-time PCR array.

Additional file 2: Summary of IPA analysis.

\section{Competing interests}

The authors have no conflicts of interest to disclose.

\section{Authors' contributions}

PJ designed and directed the study. TYF finished the most of the experiments. WJ, FX and LYH, coordinated data collection and quality control, and assisted in the interpretation of results. WD, $P L, Z W L, L J$ and $W N$ participated in acquiring laboratory data analysis. NJ participated in study design and coordination, data analysis and interpretation and drafted the manuscript. All authors read and approved the final manuscript. 


\section{Acknowledgements}

This work was supported by grants from the National Key Basic Research Program No. 2010CB933902, National Natural Science Foundation for youth No. 81100371, Natural Science Foundation of Jiangsu Province No. BK2011308, Universities Natural Science Foundation of Jiangsu Province No. $11 \mathrm{KJB} 320014$ and Talent's subsidy project in science and education of department of public health of Suzhou City No. SWKQ1020. Medical innovation team and leading talent of Jiangsu Province. No. L201126. Major scientific and technological special project for "significant new drugs creation" No. 2012ZX09103301-040

Received: 16 August 2012 Accepted: 6 September 2012

Published: 8 September 2012

\section{References}

1. Estey E, Dohner H: Acute myeloid leukaemia. Lancet 2006, 368(9550):1894-1907.

2. Foran JM: New prognostic markers in acute myeloid leukemia: perspective from the clinic. Hematology Am Soc Hematol Educ Program 2010, 1:47-55.

3. Wang $X$, Gotoh O: Accurate molecular classification of cancer using simple rules. BMC Med Genomics 2009, 2:64.

4. Haouas H, Haouas S, Uzan G, Hafsia A: Identification of new markers discriminating between myeloid and lymphoid acute leukemia. Hematology 2010, 15(4):193-203.

5. Chun SM, Kim YL, Choi HB, Oh YT, Kim YJ, Lee S, Kim TG, Yang EG, Park YK, Kim DW, et al: Identification of leukemia-specific fusion gene transcripts with a novel oligonucleotide array. Mol Diagn Ther 2007, 11(1):21-28.

6. Steinbach D, Schramm A, Eggert A, Onda M, Dawczynski K, Rump A, Pastan I, Wittig S, Pfaffendorf N, Voigt A, et al: Identification of a set of seven genes for the monitoring of minimal residual disease in pediatric acute myeloid leukemia. Clin Cancer Res 2006, 12(8):2434-2441.

7. Schena M, Shalon D, Davis RW, Brown PO: Quantitative monitoring of gene expression patterns with a complementary DNA microarray. Science 1995, 270(5235):467-470

8. Bresolin S, Zecca M, Flotho C, Trentin L, Zangrando A, Sainati L, Stary J, de Moerloose B, Hasle H, Niemeyer CM, et al: Gene expression-based classification as an independent predictor of clinical outcome in juvenile myelomonocytic leukemia. J Clin Oncol 2010, 28(11):1919-1927.

9. de Jonge HJ, Huls G, de Bont ES: Gene expression profiling in acute myeloid leukaemia. Neth J Med 2011, 69(4):167-176.

10. Kolquist KA, Schultz RA, Furrow A, Brown TC, Han JY, Campbell LJ, Wall M, Slovak ML, Shaffer $L G$, Ballif BC: Microarray-based comparative genomic hybridization of cancer targets reveals novel, recurrent genetic aberrations in the myelodysplastic syndromes. Cancer Genet 2011, 204(11):603-628.

11. Gershon D: Microarray technology: an array of opportunities. Nature 2002, 416(6883):885-891.

12. Majtan T, Bukovska G, Timko J: DNA microarrays-techniques and applications in microbial systems. Folia Microbiol (Praha) 2004, 49(6):635-664.

13. Whetten $R$, Sun $Y H$, Zhang $Y$, Sederoff R: Functional genomics and cell wall biosynthesis in loblolly pine. Plant Mol Biol 2001, 47(1-2):275-291.

14. Huang JX, Mehrens D, Wiese R, Lee S, Tam SW, Daniel S, Gilmore J, Shi M, Lashkari D: High-throughput genomic and proteomic analysis using microarray technology. Clin Chem 2001, 47(10):1912-1916.

15. Pusztai L, Hess KR: Clinical trial design for microarray predictive marker discovery and assessment. Ann Oncol 2004, 15(12):1731-1737.

16. Simon R, Radmacher MD, Dobbin K: Design of studies using DNA microarrays. Genet Epidemiol 2002, 23(1):21-36.

17. Stoeck T, Hayward B, Taylor GT, Varela R, Epstein SS: A multiple PCR-primer approach to access the microeukaryotic diversity in environmental samples. Protist 2006, 157(1):31-43.

18. Vinuela A, Snoek LB, Riksen JA, Kammenga JE: Genome-wide gene expression analysis in response to organophosphorus pesticide chlorpyrifos and diazinon in C. elegans. PLoS One, 5(8):e12145.

19. Arikawa E, Sun Y, Wang J, Zhou Q, Ning B, Dial SL, Guo L, Yang J: Crossplatform comparison of SYBR Green real-time PCR with TaqMan PCR, microarrays and other gene expression measurement technologies evaluated in the MicroArray Quality Control (MAQC) study. BMC Genomics 2008, 9:328.
20. Geets J, de Cooman M, Wittebolle L, Heylen K, Vanparys B, De Vos P, Verstraete $\mathrm{W}$, Boon N: Real-time PCR assay for the simultaneous quantification of nitrifying and denitrifying bacteria in activated sludge. Appl Microbiol Biotechnol 2007, 75(1):211-221.

21. Ramalingam N, Liu HB, Dai CC, Jiang Y, Wang H, Wang Q, MH K, Gong HQ: Real-time PCR array chip with capillary-driven sample loading and reactor sealing for point-of-care applications. Biomed Microdevices 2009, 11(5):1007-1020

22. Schmittgen TD, Lee EJ, Jiang J: High-throughput real-time PCR. Methods Mol Biol 2008, 429:89-98.

23. Oto OA, Paydas S, Tanriverdi K, Seydaoglu G, Yavuz S, Disel U: Survivin and EPR-1 expression in acute leukemias: prognostic significance and review of the literature. Leuk Res 2007, 31(11):1495-1501.

24. Barragan E, Cervera J, Bolufer P, Ballester S, Martin G, Fernandez P, Collado R, Sayas MJ, Sanz MA: Prognostic implications of Wilms' tumor gene (WT1) expression in patients with de novo acute myeloid leukemia. Haematologica 2004, 89(8):926-933.

25. Wojcik I, Szybka M, Golanska E, Rieske P, Blonski JZ, Robak T, Bartkowiak J: Abnormalities of the P53, MDM2, BCL2 and BAX genes in acute leukemias. Neoplasma 2005, 52(4):318-324.

26. Nicolas E, Ramus C, Berthier S, Arlotto M, Bouamrani A, Lefebvre C, Morel F, Garin J, Ifrah N, Berger F, et al: Expression of S100A8 in leukemic cells predicts poor survival in de novo AML patients. Leukemia 2011, 25(1):57-65.

27. Haidar MA, Cao XB, Manshouri T, Chan LL, Glassman A, Kantarjian HM, Keating MJ, Beran MS, Albitar M: p16INK4A and p15INK4B gene deletions in primary leukemias. Blood 1995, 86(1):311-315.

28. Kapelko-Slowik K, Wolowiec D, Sedek K, Jazwiec B, Urbaniak-Kujda D, Kuliczkowski K: [Expression of p16INK4a, p15INK4b, p21WAF1/Clip1 cell cycle inhibitors on blastic cells in patients with acute myeloblastic leukemia (AML) and acute lymphoblastic leukemia (ALL)]. Pol Arch Med Wewn 2002, 108(3):849-853.

29. Preisler HD, Li B, Chen H, Fisher L, Nayini J, Raza A, Creech S, Venugopal P: P15INK4B gene methylation and expression in normal, myelodysplastic, and acute myelogenous leukemia cells and in the marrow cells of cured lymphoma patients. Leukemia 2001, 15(10):1589-1595.

30. Schwaller J, Pabst T, Koeffler HP, Niklaus G, Loetscher P, Fey MF, Tobler A: Expression and regulation of G1 cell-cycle inhibitors (p16INK4A, p15INK4B, p18INK4C, p19INK4D) in human acute myeloid leukemia and normal myeloid cells. Leukemia 1997, 11(1):54-63.

31. Wang L: [Resistance of leukemia cells to Fas/FasL-mediated apoptosis and strategies replying to antiapoptosis of leukemia cells-review]. Zhongguo Shi Yan Xue Ye Xue Za Zhi 2007, 15(6):1325-1329.

32. Chauchereau A, Mathieu M, de Saintignon J, Ferreira R, Pritchard LL, Mishal Z, Dejean A, Harel-Bellan A: HDAC4 mediates transcriptional repression by the acute promyelocytic leukaemia-associated protein PLZF. Oncogene 2004, 23(54):8777-8784.

33. Gao C, Cheng X, Lam M, Liu Y, Liu Q, Chang KS, Kao HY: Signal-dependent regulation of transcription by histone deacetylase 7 involves recruitment to promyelocytic leukemia protein nuclear bodies. Mol Biol Cell 2008, 19(7):3020-3027.

34. Xu X, Xie C, Edwards H, Zhou H, Buck SA, Ge Y: Inhibition of histone deacetylases 1 and 6 enhances cytarabine-induced apoptosis in pediatric acute myeloid leukemia cells. PLoS One, 6(2):e17138.

35. Moreno DA, Scrideli CA, Cortez MA, de Paula Queiroz R, Valera ET, da Silva Silveira V, Yunes JA, Brandalise SR, Tone LG: Differential expression of HDAC3, HDAC7 and HDAC9 is associated with prognosis and survival in childhood acute lymphoblastic leukaemia. Br J Haematol 2010, 150(6):665-673.

36. Kim SY, Hwang SH, Song EJ, Shin HJ, Jung JS, Lee EY: Level of HOXA5 hypermethylation in acute myeloid leukemia is associated with shortterm outcome. Korean I Lab Med 2010, 30(5):469-473.

37. Andreeff M, Ruvolo V, Gadgil S, Zeng C, Coombes K, Chen W, Kornblau S, Baron AE, Drabkin HA: HOX expression patterns identify a common signature for favorable AML. Leukemia 2008, 22(11):2041-2047.

38. Rice KL, Licht JD: HOX deregulation in acute myeloid leukemia. J Clin Invest 2007, 117(4):865-868.

39. Ohnishi K, Tobita T, Sinjo K, Takeshita A, Ohno R: Modulation of homeobox $B 6$ and $B 9$ genes expression in human leukemia cell lines during myelomonocytic differentiation. Leuk Lymphoma 1998, 31(5-6):599-608. 
40. Boucherat O, Guillou F, Aubin J, Jeannotte L: [Hoxa5: a master gene with multifaceted roles]. Med Sci (Paris) 2009, 25(1):77-82.

41. Zangenberg M, Grubach L, Aggerholm A, Silkjaer T, Juhl-Christensen C, Nyvold CG, Kjeldsen E, Ommen HB, Hokland P: The combined expression of HOXA4 and MEIS1 is an independent prognostic factor in patients with AML. Eur J Haematol 2009, 83(5):439-448.

42. Addeo R, Caraglia M, Baldi A, D'Angelo V, Casale F, Crisci S, Abbruzzese A, Vincenze B, Campioni M, Di Tullio MT, et al: Prognostic role of bcl-xL and p53 in childhood acute lymphoblastic leukemia (ALL). Cancer Biol Ther 2005, 4(1):32-38.

43. Blau O, Avigad S, Stark B, Kodman Y, Luria D, Cohen IJ, Zaizov R: Exon 5 mutations in the $p 53$ gene in relapsed childhood acute lymphoblastic leukemia. Leuk Res 1997, 21(8):721-729.

44. Felix CA, Hosler MR, Provisor D, Salhany K, Sexsmith EA, Slater DJ, Cheung NK, Winick NJ, Strauss EA, Heyn R, et al: The p53 gene in pediatric therapyrelated leukemia and myelodysplasia. Blood 1996, 87(10):4376-4381.

45. Gump J, McGavran L, Wei Q, Hunger SP: Analysis of TP53 mutations in relapsed childhood acute lymphoblastic leukemia. J Pediatr Hematol Oncol 2001, 23(7):416-419.

46. Gustafsson B, Christenson B, Hjalmar V, Winiarski J: Cellular expression of MDM2 and p53 in childhood leukemias with poor prognosis. Med Pediatr Oncol 2000, 34(2):117-124.

47. Kattamis AC, Tsangaris GT, Vamvoukakis J, Moschovi M, Grafakos S, Tzortzatou-Stathopoulou F: Detection of minimal residual disease by mutant p53 immunocytochemistry in acute myelogenous leukemia. Med Pediatr Oncol 2000, 34(2):153-156.

48. Kawamura M, Ohnishi H, Guo SX, Sheng XM, Minegishi M, Hanada R, Horibe K, Hongo T, Kaneko Y, Bessho F, et al: Alterations of the p53, p21, p16, p15 and RAS genes in childhood T-cell acute lymphoblastic leukemia. Leuk Res 1999, 23(2):115-126.

49. Saito S, Matsuda K, Taira C, Sano K, Tanaka-Yanagisawa M, Yanagisawa R, Nakazawa Y, Sakashita K, Shiohara M, Koike K: Genetic analysis of TP53 in childhood myelodysplastic syndrome and juvenile myelomonocytic leukemia. Leuk Res 2011, 35(12):1578-1584.

50. Zhu N, Gu L, Findley HW, Chen C, Dong JT, Yang L, Zhou M: KLF5 Interacts with $p 53$ in regulating survivin expression in acute lymphoblastic leukemia. J Biol Chem 2006, 281(21):14711-14718.

doi:10.1186/1475-2867-12-40

Cite this article as: Yan-Fang et al: Analyzing the gene expression profile of pediatric acute myeloid leukemia with real-time PCR arrays.

Cancer Cell International 2012 12:40.

\section{Submit your next manuscript to BioMed Central and take full advantage of:}

- Convenient online submission

- Thorough peer review

- No space constraints or color figure charges

- Immediate publication on acceptance

- Inclusion in PubMed, CAS, Scopus and Google Scholar

- Research which is freely available for redistribution 